\title{
Analisis Sentimen Wisata Jawa Tengah Menggunakan Naïve Bayes
}

\author{
Rifan Ferryawan ${ }^{1}$, Kusrini ${ }^{2}$, Ferry Wahyu Wibowo ${ }^{3}$ \\ ${ }^{1,2,3}$ Magister Teknik Informatika Universitas Amikom Yogyakarta \\ Email : ${ }^{1}$ rifan.cclub@gmail.com, ${ }^{3}$ kusrini@amikom.ac.id, ${ }^{3}$ ferry.w@amikom.ac.id
}

\begin{abstract}
Abstrak
Penerapan teknologi oleh pemerintah dalam meningkatkan industri pariwisata di Jawa Tengah tidak dapat dipisahkan. Melalui media sosial, salah satunya Twitter, pengunjung dapat berbagi informasi dan opini melalui membagikan pesan maupun aktif berkomentar. Informasi seputar fasilitas dan pelayanan pariwisata, pengalaman pengunjung, opini dan foto yang diabadikan di upload dari obyek wisata, dapat dikelola menjadi informasi yang bermanfaat, salah satunya untuk mengetahui peningkatan mutu fasilitas dan pelayanan pada obyek wisata. Penelitian ini dapat digunakan untuk membuat kebijakan yang diberlakukan pada obyek wisata dengan memanfaatkan hasil analisis sentimen. Peneliti menggunakan pendekatan strategi klasifikasi algorima naïve bayes karena merupakan metode sederhana yang kinerjanya mirip dengan pendekatan lain. Berdasarkan penelitianpenelitian yang telah ada, Naïve Bayes menggabungkan efisiensi waktu dan kinerja yang optimal serta cukup akurat.
\end{abstract}

Kata Kunci:pariwisata, sentimen, naive bayes

\section{PENDAhULUAN}

Media sosial merupakan media daring yang digunakan oleh para penggunanya sebagai sarana pergaulan sosial secara online di internet. Dalam media sosial, para penggunanya dapat saling bertukar informasi, berdiskusi, berkomunikasi, berinteraksi, dan melakukan kegiatan lain. Media sosial dengan teknologi berbasis aplikasi maupun website dapat mengubah suatu komunikasi ke dalam bentuk dialog yang interaktif. Salah satu media sosial banyak digunakan adalah Twitter.

Dampak positif media sosial dalam perkembangan information technology (IT) sebenarnya membawa banyak keuntungan, misalnya saja memudahkan dalam hal komunikasi, mencari dan mengakses informasi. Sentiment analysis menjadi salah satu cabang riset yang berkembang dari situasi ledakan informasi yang beredar salah satunya informasi di internet. Opinion mining atau sentiment analysis merupakan studi komputasional yang diperoleh dari opini-opini orang, appraisal dan emosi melalui entitas, event dan atribut yang dimiliki (Liu, 2012).

Penelitian terdahulu yang terkait dengan sentiment analysis, antara lain adalah penelitian (Pak, Alexander and Paroubek, 2010) tentanf menganalisis twitter sebagai linguistik korpus untuk sentiment analysis.
Pada penelitian (Gamallo, Pablo, \& FernandezLanza, 2013) tentang strategi naïve bayes dalam sentiment analysis untuk tweet berbahasa Spanyol. Penelitian (Vinodhini and Chandrasekaran, 2012) tentang pengembangan sistem yang dapat mengidentifikasi dan mengklasifikasikan sentimen masyarakat untuk memprediksi produk yang menarik dalam pemasaran.

Pada penelitian ini, sentiment analysis akan digunakan untuk menentukan persepsi masyarakat terhadap obyek wisata berdasarkan data komentar atau opini yang terdapat di twitter yang membicarakan tentang suatu tempat pariwisata. Peneliti menggunakan strategi klasifikasi berdasarkan pada algorima Naive Bayes karena metode tersebut sederhana dan efisiensi waktu kinerja yang optimal dengan akurasi yang cukup akurat.

Agar dalam pembahasan penelitian nantinya lebih terarah dan sesuai dengan yang diharapkan maka pada penelitian merumuskan batasan masalah sebagai berikut:

1. Peneliti menetapkan point of interest (POI) atau spesifik lokasi dari obyek wisata yaitu sebanyak 10 POI di Jawa Tengah.

2. Sebagai sumber data, informasi di crawling dari media sosial twitter. 
3. Data yang dianalisis hanya tweet dalam format bahasa Indonesia dan dengan kata kunci yang berhubungan dengan POI.

4. Metode klasifikasi yang digunakan untuk mengklasifikasikan tweet adalah metode Naïve Bayes Classifier.

\section{METODE PENELITIAN}

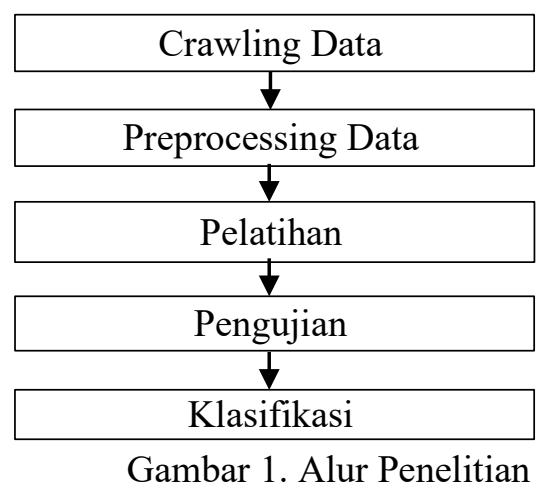

Proses analisis sentimen mencakup dua proses yaitu pra-proses dan klasifikasi sentimen. Pra-proses merupakan proses untuk mempersiapkan data menjadi format yang lebih mudah untuk diproses pada klasifikasi sentimen. Klasifikasi sentiment merupakan proses menentukan kelas sentiment data. Setiap model analisis sentiment memerlukan tahapan pra-proses yang berbeda. Tahap pra-proses pada model analisis sentiment dibagi menjadi tujuh proses, yaitu: pengambilan tweet, tokenisasi, mengartikan singkatan, filtrasi, lematisasi atau stemming, dan membuat unigram dan bigram. Setiap tahapan pra-proses harus diterapkan pada data latih, data uji, dan data asli agar format yang dihasilkan sama. Langkah yang dilakukan setelah pra-proses adalah klasifikasi sentiment dengan menggunakan pendekatan lexicon kemudian hasil klasifikasi tersebut diolah kembali menggunakan algoritma Nä̈ve Bayes Classifier.

\section{TINJAUAN PUSTAKA}

Dalam penelitian yang dilakukan oleh Said A. Salloum, Chaker Mhamdi, Mostafa AlEmran, dan Khaled Shaalan tahun 2017 yang berjudul "Anaylisis and Classification of Arabic Newspapers' Facebook Pagers using Text Mining Techniques" memaparkan bahwa proses pengumpulan data menggunakan 62327 posting dari 24 halaman surat kabar di
Facebook di negara-negara Teluk Arab yang kemudian diekstraksi dan dianalisis. Posting dengan substansi yang hilang atau teks yang tidak konsisten dihapus saat membersihkan dataset selama pemrosesan data. Perangkat lunak Facepager digunakan untuk mengumpulkan data. Penyiapan kueri digunakan untuk mengumpulkan URL. Selanjutnya, database data lokal yang tersimpan diekstraksi dan diekspor ke format CSV. Untuk meningkatkan kualitas dan kinerja data, atribut yang tidak relevan dikeluarkan saat mengimpor dataset ke software RapidMiner. Untuk meningkatkan presisi, atribut yang hilang adalah dihapus dari dataset selama tahap analisis. (Said A. Salloum, 2017) Andrey Maureen Pudjajana dan Danny Manongga tahun 2018 dalam penelitiannya yang berjudul "Sentimen Analisis Tweet Pornografi Kaum Homoseksual Indonesia di Twitter dengan Naive Bayes", dijelaskan bahwa penelitian ini dimulai dengan menganalisis dan menentukan hashtag (\#) yang sering muncul di Twitter yang berkaitan dengan homoseksual di Indonesia. Pengumpulan data dilakukan berdasarkan hashtag Twitter yang telah dipilih. Data didapat dengan mengunakan Twitter API dengan tools yang digunakan yaitu Rapidminer Studio versi 7.6.1. Data-data tersebut disimpan ke Microsoft Excel 2016 dimana setiap hashtag terdiri dari 500 data. Kemudian melakukan proses proprocessing. Penelitian ini membagi data-data yang telah dilakukan proses preprocessing menjadi dua bagian yaitu data latih dan data uji. Pembuatan data latih ini bertujuan sebagai pedoman dalam menentukan hasil data uji dan pada penelitian ini menggunakan 200 data data latih untuk setiap hashtag. Data uji penelitian ini diujikan secara manual dan berdasarkan data latih yang telah dibuat dengan menggunakan metode Naïve Bayes. Hasil dari pengujian tersebut akan berupa $\mathrm{P}=$ sentimen postif dan $\mathrm{N}=$ sentimen negatif. Selain itu, hasil perhitungan Naïve Bayes dibandingkan dengan hasil perhitungan k-Nearest Neighbor (k-NN) untuk mengetahui tingkat keakurasian metode Naïve Bayes dalam penelitian ini. Hasil perbandingan kedua metode tersebut berdasarkan total rata-rata pengujian kelima hashtag adalah Naïve Bayes sebesar $87.48 \%$, dan k-NN sebesar $85.40 \%$. (Manongga, 2018)

Penelitian tahun 2018 yang dilakukan oleh Teguh Ansyor Lorosae, Burhanudin Dwi 
Prakoso, Saifudin, dan Kusrini dengan judul "Analisis Sentimen Berdasarkan Opini Masyarakat Pada Twitter Menggunakan Naive Bayes" melakukan analisis sentimen pada jasa pengiriman TIKI. Data masukan berupa data latih dan data uji yang digunakan bersumber dari fanpage akun twitter perusahaan jasa ekspedisi TIKI berupa opini-opini masyarakat mengenai pelayanan jasa tersebut. Pada tahap pra-proses terdiri dari convert emoticon, case folding, tokenizing, stemming serta filtering. Data yang telah diproses pada pra-proses diproses kembali dengan menggunakan metode naïve bayes. Berdasarkan dari hasil penelitian yang telah dilakukan, dapat disimpulkan bahwa penelitian ini telah menghasilkan sebuah sistem analisis sentimen jasa pengiriman barang menggunakan naïve bayes. Sistem yang dibangun telah mampu mentransformasi sentimen yang berupa teks opini pada fanpage Tiki sehingga dapat menampilkan informasi sentimen masyarakat terhadap jasa pengiriman barang yang bersifat positif, negatif dan netral. Penggunaan metode naïve bayes classifier pada penelitian ini tidak menjamin ketepatan dalam proses klasifikasi. Akurasi pada sistem yang dibangun mencapai $84 \%$. Tingkat akurasi akan semakin baik bila data latih yang digunakan lebih banyak, jumlah kategori pada setiap kelas sentimen pun akan berpengaruh. (Teguh Ansyor Lorosae, 2018)

\section{a. Analisis Sentimen}

Analisis sentimen juga dikenal sebagai opinion mining atau emotion artificial intelligence adalah penggunaan pemprosesan bahasa alami, analisis teks, komputasi linguistik dan biometrik untuk mengidetifikasi, mengekstrak, menghitung dan mempelajari informasi subjektif secara sistematis (Rizal, 2017).

\section{b. Twitter}

Twitter adalah situs web dimiliki dan dioperasikan oleh Twitter, Inc., yang menawarkan jaringan sosial berupa microblog. Disebut microblog karena situs ini memungkinkan penggunanya mengirim dan membaca pesan blog seperti pada umumnya namun terbatas hanya sejumlah 140 karakter yang ditampilkan pada halaman profil pengguna.. Twitter memiliki karakteristik dan format penulisan yang unik dengan simbol ataupun aturan khusus.Pesan dalam Twitter dikenal dengan sebutan tweet (Aliandu, 2013).
Berikut ini adalah beberapa istilah yang dikenal dalam Twitter:

a. Mention

Mention adalah menyebut atau memanggil pengguna Twitter lain dalam sebuah tweet. Mention dilakukan dengan menuliskan '@' diikuti dengan nama pengguna lain.

b. Hashtag

Hashtag digunakan untuk menandai sebuah topik pembicaraan di Twitter. Penulisan hashtag dimulai dengan tanda '\#' diikuti dengan topik yang sedang dibahas. Hashtag biasa digunakan untuk meningkatkan visibilitas tweet pengguna.

\section{c. Emoticon}

Emoticon adalah ekspresi wajah yang direpresentasikan dengan kombinasi antara huruf, tanda baca dan angka. Pengguna biasa menggunakan emoticon untuk mengekspresikan mood yang sedang mereka rasakan.

\section{d. Trending Topics}

Jika hashtag adalah cara untuk menandai sebuah topik pembicaraan di Twitter, maka trending topics adalah kumpulan dari topik pembicaraan yang sangat populer di Twitter.

\section{c. Konsep Naïve Bayes Classifier (NBC)}

Naïve Bayes Classifier merupakan salah satu metoda machine learning yang memanfaatkan perhitungan probabilitas dan statistik yang dikemukakan oleh ilmuwan Inggris Thomas Bayes, yaitu memprediksi probabilitas di masa depan berdasarkan pengalaman di masa sebelumnya (Antonius Rachmat C, 2016). Dasar dari Nä̈ve Bayes yang dipakai dalam pemrograman adalah rumus Bayes:

$$
\mathrm{P}(\mathrm{A} \mid \mathrm{B})=(\mathrm{P}(\mathrm{B} \mid \mathrm{A}) * \mathrm{P}(\mathrm{A})) / \mathrm{P}(\mathrm{B})
$$

Peluang kejadian A sebagai B ditentukan dari peluang $\mathrm{B}$ saat $\mathrm{A}$, peluang $\mathrm{A}$, dan peluang $B$. Pada pengaplikasiannya nanti rumus ini berubah menjadi :

$$
\mathrm{P}(\mathrm{Ci} \mid \mathrm{D})=(\mathrm{P}(\mathrm{D} \mid \mathrm{Ci}) * \mathrm{P}(\mathrm{Ci})) / \mathrm{P}(\mathrm{D})
$$

Naïve Bayes Classifier atau bisa disebut sebagai Multinomial Naïve Bayes merupakan model penyederhanaan dari Metode Bayes yang cocok dalam pengklasifikasian teks atau dokumen. Persamaannya adalah:

$\mathrm{VMAP}=\arg \max \mathrm{P}(\mathrm{Vj} \mid \mathrm{a} 1, \mathrm{a} 2, \ldots \ldots . . \mathrm{an})(3)$

Menurut persamaan (3), maka persamaan (1) dapat ditulis: 
(4)

$$
V_{M A P}=\underset{V j E^{v}}{\operatorname{agr} \max } \quad \frac{P(a 1, a 2, \ldots \ldots \ldots a n \mid p(V j)}{P(a 1, a 2, \ldots \ldots \ldots a n}
$$

Untuk $\mathrm{P}(\mathrm{x} 1, \mathrm{x} 2, \mathrm{x} 3, \ldots \mathrm{xn})$ nilainya konstan untuk semua kategori $(\mathrm{Vj})$ sehingga persamaan dapat ditulis sebagai berikut :

$$
\begin{aligned}
& V_{M A P}= \\
& \operatorname{\operatorname {max}^{v}} P\left(X_{1}, X_{2}, \ldots \ldots \ldots X_{n} \mid V j\right) P(V j)
\end{aligned}
$$

Persamaan diatas dapat disederhanakan menjadi sebagai berikut :

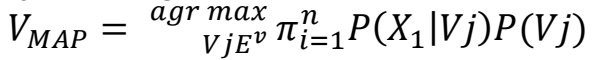

Keterangan :

$\mathrm{Vj}=$ Kategori Headline

$\mathrm{J}=1,2,3, \ldots \mathrm{n}$. Dimana dalam penelitian ini

$\mathrm{j} 1=$ kategori headline sentimen positif

$\mathrm{j} 2$ = kategori headline sentimen negatif

j3 = kategori headline sentiment netral

$\mathrm{P}(\mathrm{xi} \mid \mathrm{Vj})=$ Probabilitas xi pada kategori $\mathrm{Vj}$

$\mathrm{Vj} P(\mathrm{Vj})=$ Probabilitas dari $\mathrm{Vj}$

Untuk $\mathrm{P}(\mathrm{Vj})$ dan $\mathrm{P}(\mathrm{xi} \mid \mathrm{Vj})$ dihitung pada saat pelatihan dimana persamaannya adalah sebagai berikut :

$$
P(V j)=\frac{\mid \text { docs } j \mid}{\mid \text { contoh } \mid}
$$

Jika $\mathrm{P}(\mathrm{Vj})$ sudah ditentukan maka hitung jumlah dokumen setiap kategeri $\mathrm{j}$ dan jumlah dokumen dari semua kategori dengan menggunakan persamaan 7. diatas.

$$
P(x i \mid V j)=\frac{n k+1}{n k+\mid \text { konstanta } \mid}
$$

Keterangan :

$\mid$ docs $\mathrm{j} \mid=$ jumlah dokumen setiap kategori $\mathrm{j}$ |contoh $\mid=$ jumlah dokumen dari semua kategori kata

$\mathrm{nk}=$ jumlah frekuensi kemunculan setiap

$\mathrm{n}=$ jumlah frekuensi kemunculan kata dari setiap kategori

$\mid$ kosakata $\mid=$ jumlah semua kata dari semua kategori

Jika $\mathrm{P}(\mathrm{xi} \mid \mathrm{Vj})$ sudah ditentukan maka hitung jumlah frekuensi kemunculan setiap kata ditambah 1 dan jumlah frekuensi kemunculan kata dari setiap kategori dengan menggunakan persamaan 8 . diatas.

\section{d. Proses Text Preprocessing}

Proses text prepocessing merupakan implementasi dari text mining untuk memproses suatu teks yang tidak terstruktur menjadi lebih tersruktur atau dengan kata lain mempersiapkan agar teks dapat diubah menjadi lebih terstruktur. Ada empat tahapan text prepocessing yang meliputi case folding, tokenizing, filtering, dan stemming.

\section{a. Case Folding}

Tahapan case folding adalah tahapan untuk mengkonversi keseluruhan teks dalam dokumen menjadi seluruhnya huruf kecil (lowercase). Sebagai contoh, teks "PARIWISATA", "Pariwisata", "PariWisata", atau "pariwisata", tetap diberikan hasil retrieval yang sama yakni "pariwisata". Pada tahapan case folding ini hanya huruf 'a' sampai dengan ' $\mathrm{z}$ ' yang diterima, sedangkan karakter selain huruf dihilangkan dan dianggap delimiter.

b. Tokenizing

Tahapan tokenizing adalah tahap pemotongan string input berdasarkan tiap kata yang menyusunnya. Contoh dari tahap ini dapat dilihat pada Gambar 2.

Teks input

Sektor pariwisata saat ini menjadi salah satu investasi yang penting di jawa tengah

\section{Hasil tokenizing}

\begin{tabular}{|l|}
\hline Sektor \\
pariwisata \\
saat \\
ini \\
menjadi \\
salah \\
satu \\
investasi \\
yang \\
penting \\
di \\
jawa \\
tengah \\
\hline
\end{tabular}

\section{c. Filtering}

Gambar 2. Proses Tokenizing

Tahapan filtering adalah tahap mengambil kata-kata penting dari hasil token. Bisa menggunakan algoritma stoplist (membuang kata kurang penting) atau wordlist (menyimpan kata penting). Stoplist/stopword adalah kata-kata yang tidak deskriptif yang dapat dibuang dalam pendekatan bag-ofwords. Contohnya dapat dilihat pada Gambar 3. 


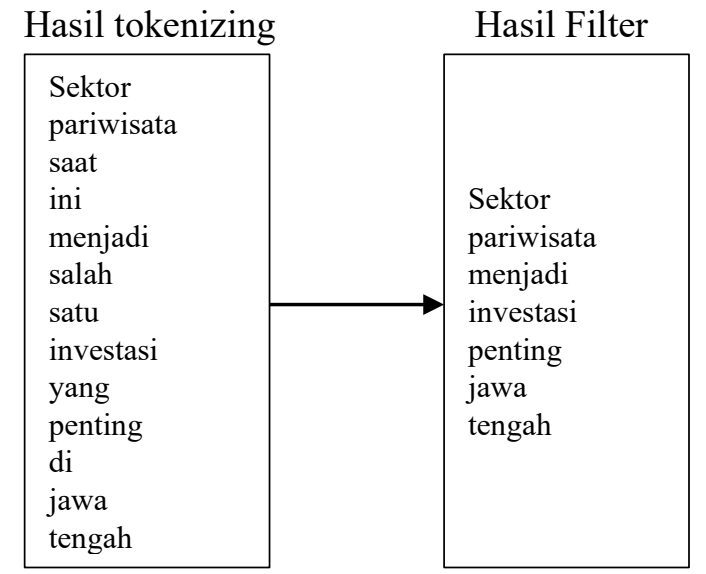

Gambar 3. Proses Filtering

\section{d. Stemming}

Teknik stemming diperlukan selain untuk memperkecil jumlah indeks yang berbeda dari suatu dokumen, juga untuk melakukan pengelompokan kata-kata lain yang memiliki kata dasar dan arti yang serupa namun memiliki bentuk atau form yang berbeda karena mendapatkan imbuhan yang berbeda.

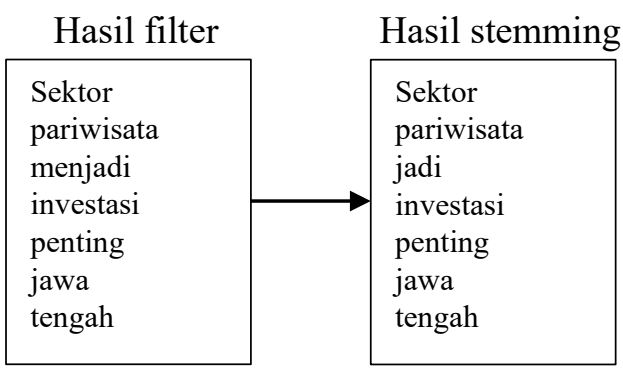

Gambar 4. Proses Stemming

\section{HASIL DAN PEMBAHASAN}

Penelitian ini dilakukan dengan mengambil opini publik tentang obyek wisata Karimunjawa di Jepara, candi Borobudur di Magelang, Gua Maria Kerep di Ambarawa, dataran tinggi Dieng di Wonosobo, kawasan wisata Baturaden di Purwokerto, Lawang Sewu di Semarang, Grojogan Sewu di Karanganyar, Umbul Ponggok di Klaten, Masjid Agung Jawa Tengah di Semarang dan pantai Karang Bolong di Kebumen dari aplikasi media sosial Twitter. Opini publik diambil secara manual pada rentang waktu 11 Mei 2019 sampai 28 Mei 2019 dan menemukan 215 opini publik. Opini publik tersebut dilabeli secara manual menjadi tiga tipe opini yaitu negatif (84 opini), netral (73 opini) dan positif (58 opini). Perhitungan yang dihasilkan oleh aplikasi yaitu 98 sentimen positif, 90 sentimen negatif dan 27 sentimen netral.

Hasil tersebut menunjukkan masyarakat lebih menunjukan sikap positif pada wisata di Jawa Tengah, akan tetapi hasil perhitungan antara sentimen positif dan sentimen negatif hanya berbeda 8 data. Perbedaan yang tidak terlalu signifikan ini patut menjadi pertimbangan bagi pemerintah untuk memperbaiki obyek wisata yang ada sebagai investasi pemerintah.

Peningkatan hasil analisa sentimen bisa diketahui dengan membandingkan antara aplikasi sentimen yang menggunakan POS Tagger dan aplikasi sentimen tanpa menggunakan POS Tagger. Aplikasi sentimen tanpa POS Tagger ini merupakan penelitian yang telah dilakukan sebelumnya dan hasil klasifikasinya kurang baik dikarenakan terdapat beberapa kekurangan (Kusumawati, 2017). Hasil perbandingan menunjukkan peningkatan yang cukup bagus pada tipe opini negatif dan positif. Aplikasi sentimen yang menggunakan POS Tagger bisa menghasilkan nilai recall 0,5 pada tipe opini negatif, sedangkan aplikasi sentimen tanpa menggunakan POS tagger menghasilkan nilai recall 0,452. Pada tipe opini

positif juga mengalami peningkatan nilai recall yang awalnya 0,327 menjadi 0,448 . Hasil dari kedua aplikasi sentimen bisa dilihat di Tabel 1 .

Tabel 1. Hasil Pengujian

\begin{tabular}{|c|c|c|c|c|c|c|}
\hline \multirow{2}{*}{ Tipe } & \multicolumn{5}{c}{ Klasifikasi } \\
Opini & \multicolumn{3}{|c}{ Tanpa POS Tagger } & \multicolumn{3}{c|}{ Menggunakan POS Tagger } \\
\hline & Negatif & Netral & Positif & Negatif & Netral & Positif \\
\hline Precision & 0,436 & 0,464 & 0,19 & 0,467 & 0,407 & 0,265 \\
\hline Recall & 0,452 & 0,178 & 0,327 & 0,5 & 0,15 & 0,448 \\
\hline Accuracy & & 0,325 & & & 0,367 & \\
\hline
\end{tabular}

Precision adalah tingkat ketepatan sistem dalam menemukan data yang relevan antara data yang diuji dan data yang dihasilkan sistem. Recall adalah keberhasilan menemukan seluruh data oleh suatu sistem. Accuracy adalah tingkat kedekatan hasil pengujian dengan nilai sebenarnya. Pada tabel hasil pengujian accuracy sistem secara keseluruhan mengalami kenaikan meskipun hanya sekitar 0,042 . Peningkatan accuracy ini sangat penting karena menunjukkan bahwa penelitian ini cukup berhasil dan sesuai dengan tujuannya yaitu meningkatkan hasil asalisa sentimen. Pada tabel pengujian tipe opini positif dan negatif mengalami kenaikan sedangkan nilai netral mengalami penurunan. Meskipun tipe 
opini positif mengalami kenaikan namun nilai precision-nya sangat rendah yaitu hanya 0,265 . Rendahnya nilai precision ini dikarenakan tweet berlabel positif paling rendah dibanding tweet berlabel netral dan negatif. Penurunan nilai precision dan recall pada tipe opini netral disebabkan dalam kamus Sentiwordnet synset yang memiliki skor 0.0 (netral) jarang ditemukan, sehingga ketika proses pertihungan sentimen nilai netral jarang muncul.

\section{KESIMPULAN}

Berdasarkan hasil analisis uji validitas data, algoritma yang digunakan sudah cukup memiliki akurasi yang baik dan dapat diterima sebagai suatu metode perhitungan pemeringkatan. Khususnya dalam domain pariwisata, komponen-komponen penilaian yang digunakan sudah dapat memberikan penilaian yang lebih objektif yang dihasilkan berdasarkan konten opini atau ulasan dari media sosial maupun situs pariwisata lainnya. Dengan mengambil data uji terhadap 10 point of interest (POI) tujuan wisata di Jawa Tengah, hasil ekstraksi dan klasifikasi opini maupun ulasan yang berkitan dengan destinasi wisata di Jawa Tengah tersebut menghasilkan persepsi masyarakat yang dapat menjadi bahan pertimbangan bagi pemerintah untuk memperbaiki fasilitas dan pelayanan pada obyek wisata.

Ada beberapa saran agar hasil penelitian ini dapat lebih baik lagi, yaitu:

1. Penelitian selanjutnya dapat dikembangkan dengan menambah beberapa fitur pada aplikasi yang dibangun agar lebih baik lagi.

2. Perlu ada perbaikan dalam metodologi pemeringkatan yang digunakan, agar hasil pemeringkatan dapat lebih akurat dan lebih baik lagi.

3. Menambah metodologi business intelegent (BI) yang dapat digunakan sebagai alat bantu pengambilan keputusan bagi yang berkepentingan, dalam hal ini khususnya pemerintah sebagai stakeholder destinasi wisata.

\section{REFERENSI}

Antonius Rachmat C, Y. L. (2016). Klasifikasi Sentimen Komentar Politik dari Facebook Page Menggunakan Naive Bayes. JUISI, 2(2), 1-9.

Efraim Turban, J. E. (2005). Decission Support Systems and Intelligent Systems. Yogyakarta: ANDI.

Hermawati, F. A. (2013). Pengolahan Citra Digital Konsep dan Teori. Yogyakarta: ANDI.

Kusrini, E. T. (2009). Algoritma Data Mining. Yogyakarta: Andi Offset.

Liu, B. (2012). Opinion Mining. Chicago: United .

Manongga, A. M. (2018). Sentimen Analisis Tweet Pornografi Kaum Homoseksual Indonesia Di Twitter Dengan Naive Bayes. SIMETRIS, 313-318.

Pattipeilohy. (2013). DSS Penentuan Calon Dosen Pembimbing dan Penguji (Studi Kasus: Teknik Informatika UNWIRA Kupang). Kupang: UNWIRA.

Said A. Salloum, C. M.-E. (2017). Analysis and Classification of Arabic Newspapers Facebook Pages using Text Mining Techniques. International Journal of Information Technology and Language Studies (IJITLS), 8-17.

Santoso, B. (2007). Data Mining : Teknik Pemanfaatan Data Untuk Keperluan Bisnis. Yogyakarta: Graha Ilmu.

Teguh Ansyor Lorosae, B. D. (2018). ANALISIS SENTIMEN BERDASARKAN OPINI MASYARAKAT PADA TWITTER MENGGUNAKAN NAÏVE BAYES. Seminar Nasional Teknologi Informasi dan Multimedia 2018, 1.10-25. 